\title{
Erratum to: Impact of Bi-Axial Shear on Atherogenic Gene Expression by Endothelial Cells
}

\author{
Amlan Chakraborty, ${ }^{1}$ Sutirtha Chakraborty, ${ }^{2}$ Venkatakrishna R. Jala, ${ }^{3}$ Jonathan M. Thomas, ${ }^{1}$ \\ M. Keith Sharp, ${ }^{4}$ R. Eric Berson, ${ }^{1}$ and Bodduluri Haribabu ${ }^{3}$ \\ ${ }^{1}$ Department of Chemical Engineering, University of Louisville, Ernst Hall \\ 106, Louisville, KY 40292, USA; ${ }^{2}$ Department of Bioinformatics and Biostatistics, University of Louisville, Louisville, KY, \\ USA; ${ }^{3}$ James Graham Brown Cancer Center and Department of Microbiology \& Immunology, University of Louisville, CTRB, \\ Room \#324, Louisville, KY 40202, USA; and ${ }^{4}$ Department of Mechanical Engineering, University of Louisville, Louisville, KY,
} USA

Erratum to: Annals of Biomedical Engineering (ㄷ 2016) DOI: 10.1007/s10439-016-1626-2

This article has been updated from its original publication to resolve a duplication of a reference and subsequent incorrect reference numbering.

Address correspondence to R. Eric Berson, Department of Chemical Engineering, University of Louisville, Ernst Hall 106, Louisville, KY 40292, USA. Electronic mail: eric.berson@ louisville.edu, h0bodd01@louisville.edu

The online version of the original article can be found under doi: 10.1007/s10439-016-1626-2. 